\title{
0 uso de animais para experimentação ainda é imprescindível
}

Maria Lúcia Zaidan Dagli', Nívea Lopes de Souza', José Luis Bernardino Merusse', Paulo Cesar Maiorka', Ângelo João Stopiglia²

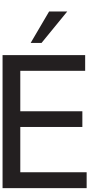

voz corrente entre muitos cientistas que o uso de animais para a experimentação ainda é imprescindível ${ }^{1}$. Entretanto, o assunto é polêmico e elicita manifestações contrárias de vários segmentos da população.

Este artigo tem por objetivo apresentar evidências de que, realmente, ainda não se pode prescindir do uso de animais em determinadas pesquisas ou para registro de novos produtos, mas que, por outro lado, há uma constante conscientização da importância de se usar procedimentos éticos, e, sempre que possível, encontrar as alternativas cabíveis.

Todos os que já estudaram história da ciência sabem que seu progresso se deveu, inicialmente, à observação de fenômenos naturais e, posteriormente, à experimentação. Claude Bernard, pai da fisiologia moderna, que viveu no século XIX, foi responsável por descobertas revolucionárias quanto ao entendimento dos princípios fundamentais da vida orgânica, os quais continuam válidos até hoje. Bernard, que redigiu o livro "Introdução ao Estudo da Medicina Experimental”, publicado em 1865, foi enormemente influente por muitas e muitas décadas a seguir.

Na verdade, a evolução observada no campo das ciências médicas e biológicas sofreu avanços significantes principalmente no século XX devido, entre outros motivos, aos trabalhos de natureza experimental levados a efeito por renomados pesquisadores, em diferentes centros de pesquisa em todo o mundo, até que os resultados obtidos pudessem ser aplicados nas rotinas clínico-cirúrgica, terapêutica e em outras.

Muitos dos ensaios experimentais em ciências biológicas se valeram de pesquisas em animais vivos. Podem ser citadas numerosas situações em que a pesquisa com animais vivos auxiliou a medicina humana. Os ensaios cirúrgicos para padronização dos transplantes de órgãos representam um excelente exemplo. Há aproximados 23 anos, a equipe comandada pelo Professor Doutor Silvano Raia realizou, no Brasil, com êxito, o primeiro transplante de fígado no homem. Porém, antes do sucesso obtido, foram necessários ensaios experimentais em mais de 450 suínos, no treinamento insistente da técnica cirúrgica e na maneira de contornar as suas complicações, para obter-se o sucesso almejado, visto que as cinco intervenções anteriores, com o mesmo objetivo, realizadas entre 1968 e 1972, não apresentaram os resultados satisfatórios esperados². Esse é apenas um dos tantos exemplos, passados e atuais, do emprego da cirurgia experimental aplicada em animais, visando obter cura para moléstias até então sem tratamento eficaz. A produção de vacinas e de soros, que salvam tantas vidas humanas hoje em dia, constitui outro importante exemplo. Como testar a eficácia de vacinas e soros, senão em animais de experimentação? Hoje em dia, sabe-se que todos os fármacos, produtos domissanitários, cosméticos, têm que ser testados quanto ao risco de toxicidade aos seres humanos e também aos animais alvo. Tais testes vêm sendo realizados em animais de laboratório. Eles permitem a produção de novos fármacos cada vez mais eficientes para o tratamento das mais diversas enfermidades, e com menos efeitos indesejáveis.

Não podemos deixar de enfatizar que os estudos experimentais vêm sendo controlados e normatizados, nas últimas décadas, pelas Comissões de Bioética nas instituições que realizam pesquisas com animais. Tais comissões avaliam os procedimentos experimentais e permitem a utilização de animais apenas quando não se dispõe de métodos alternativos. As Comissões de Bioética também desautorizam quaisquer práticas que causem sofrimento a animais vivos, e ainda proclamam a utilização do menor número possível de animais por grupo experimental.

Pode-se dizer que a legislação sobre o uso de animais de laboratório é escassa em nosso país. O Brasil não possui uma legislação que efetivamente regule a criação e o uso de animais para a pesquisa e o ensino, em âmbito nacional. Entretanto, nas páginas do Colégio Brasileiro de Experimentação Animal (COBEA) (http://www.cobea.org.br/) podem ser encontradas informações muito interessantes sobre a legislação referente a animais de laboratório em nosso país e no mundo. É indubitável a importância que o COBEA representa para a ciência em nosso país, por meio de seu lema "Desenvolvimento da ciência através do conhecimento, promoção do bem estar e uso ético de animais de laboratório”.

Na legislação internacional, estabeleceu-se a importância de se utilizar alternativas ao uso de animais sempre que possível. Assim, preconiza-se o princípio dos "três Rs", estabelecido por Russel e Burch, em 1959. "Replacement, refinement and reduction". Replacement significa a substituição de animais de laboratório sempre que possível. Deste modo, cultivos celulares, microorganismos, plantas, ovos, répteis, anfíbios ou invertebrados podem ser usados em alguns estudos para substituir, por

\footnotetext{
Departamento de Patologia

2 Departamento de Cirurgia da Faculdade de Medicina Veterinária e Zootecnia da Universidade de São Paulo, São Paulo (SP), Brasil. E-mail: mlzdagli@usp.br
} 
exemplo, o uso de mamíferos. Refinement significa o refinamento dos protocolos experimentais de forma a evitar seu sofrimento. Por exemplo, usar analgesia e anestesia para evitar a dor e o estresse dos animais. Nesse contexto, o treinamento adequado dos técnicos e de todo o pessoal envolvido é fundamental. Finalmente, reduction preconiza o uso do menor número possível de animais nos experimentos. Consultar um estatístico para calcular o número de animais mais adequado pode ser um procedimento importante para este critério. Portanto, graças ao bom senso e à conscientização de grande parte dos nossos pesquisadores e professores, foram adotados alguns princípios éticos fundamentais e imprescindíveis e buscou-se obter recomendações, no nível internacional, e são elas que hoje norteiam as boas práticas do bioterismo nacional.

A verdade é que não se pode abrir mão, ainda, da experimentação com animais no campo das ciências biológicas. Há métodos alternativos para estudo de determinados fenômenos isolados, porém estes têm valor limitado. É impossível substituir ou criar artificialmente a complexidade de um organismo como um todo, e as inúmeras interrelações fisiológicas entre os sistemas nele existentes. Um exemplo refere-se a estudos de angiogênese in vitro, ou o uso de órgãos isolados para estudos de fisiologia. O uso de culturas celulares não substitui os estudos em animais, mas apenas os complementa. Como bem sabe quem trabalha com cultivos celulares, a maioria dos testes precisa ser validada em seres vivos, antes de haver uma recomendação terapêutica.

Ainda, o que dizer dos estudos para avaliação dos riscos ambientais, ou dos estudos de potenciais agentes cancerígenos? Tais estudos têm de ser efetuados com a participação de animais de laboratório, inclusive com a demanda da Agência Nacional de Vigilância Sanitária (ANVISA). Seriam seguros aqueles produtos que informam no rótulo que não foram testados em animais?

É necessário informar que existem numerosos programas em agências de fomento americanas e européias para financiar pesquisas que busquem alternativas para o uso de animais em experimentação.

Apesar de todas essas iniciativas, existem grupos que insistem em criticar infundadamente a experimentação com animais. Projetos de lei que visam a normatização ao emprego dos animais para ensino e pesquisa (e mesmo para aqueles criados para consumo), como no caso da Lei n ${ }^{\circ} 11.977$, de 25/08/2005, que institui o Código de Proteção aos Animais do Estado de São Paulo e dá outras providências têm sido apresentados, no momento, no Supremo Tribunal Federal, com pedido de Ação Direta de Inconstitucionalidade. Na cidade do Rio de
Janeiro, foi recentemente aprovada uma lei que impede a utilização de animais em experimentação. A comunidade científica carioca se mobilizou para minimizar os efeitos desta lei. Além disso, em 2007, vereadores de Florianópolis proibiram o uso de animais em práticas de ensino e pesquisa.

A conseqüência da aplicação efetiva de leis que não são discutidas, previamente, com aguçado senso crítico, por parte de todos os segmentos envolvidos no asssunto, pode significar a estagnação do desenvolvimento das ciências biológicas, médicas e veterinárias, por falta de pesquisa nos respectivos estados ou cidades. O prejuízo à ciência em nosso país seria incomensurável.

A Faculdade de Medicina Veterinária e Zootecnia, cujo curso de Medicina Veterinária apresenta excelentes indicadores de avaliação em todos os levantamentos oficiais realizados nos últimos anos, tem pela sua concepção, natureza e pelos aspectos éticos da profissão, a necessidade e o cuidado de difundir e empregar os conceitos de bem-estar animal. Por este motivo, aperfeiçoa e propaga meios alternativos ao emprego de animais vivos em atividades didáticas, atitude que mereceu, ainda recentemente, na Inglaterra, a atribuição de um prêmio a uma professora desta Faculdade ${ }^{3}$.

Por outro lado, por ser uma Unidade da Universidade de São Paulo, que tem em seus objetivos o ensino, a pesquisa e a extensão universitária, e ainda, pertencer a Medicina Veterinária ao domínio das Ciências Biológicas, entende que neste campo de atuação, a pesquisa não pode prescindir da experimentação com animais vivos. Salientamos também que a Faculdade de Medicina Veterinária e Zootecnia da Universidade de São Paulo possui Comissão de Bioética, que tem a função de analisar todos os projetos de pesquisa conduzidos nesta faculdade, bem como os protocolos utilizados no ensino, certificando-se de que todos os procedimentos sejam conduzidos dentro do mais rigoroso padrão ético.

Assim, a Faculdade de Medicina Veterinária e Zootecnia, reitera que preserva e difunde as boas práticas do bem-estar animal e os adequados procedimentos de experimentação com animais vivos. Entende também que há a necessidade de continuidade da experimentação científica com animais vivos, sem, contudo deixar de lado os padrões éticos.

Por fim, acreditamos que posições radicais não se coadunam com o moderno estado de direito, pois impedem a discussão serena e ponderada de um tema tão fundamental à evolução da ciência. A experimentação ética com animais não pode deixar de lado o bem-estar animal, e ao mesmo tempo pode proporcionar o bem de toda a humanidade.

\section{Referências}

1. Marques F. Sem eles não há avanço. Revista Pesquisa Fapesp fev 2008;14:25 -31.

2. Lopes AD. Os 20 anos do transplante de fígado. ESP, $1^{\circ}$ caderno, 2005; 26
3. Silva RM, Matera JM, Ribeiro AA. New alternative methods to teach surgical techniques for veterinary medicine students despite the absence of living animals. Is that an academic paradox? Anat Histol Embryol 2007;36(3):220-4 . 